\title{
The City Competitive Analysis of Poyang Lake Ecological Economic Zone Based On AHP Analytic Hierarchy Process
}

\author{
Wei $\mathrm{Lu}^{1, \mathrm{a}}$ \\ ${ }^{1}$ The center for Social Studies of Wuhan University, Hubei Wuhan 430027; China \\ a124993555@qq.com
}

Keywords: Urban competitiveness; Ecological Economic Zone; Poyang Lake

\begin{abstract}
The establishment of Poyang Lake Ecological Economic Zone is an important measure to protect the Poyang Lake ecological resources, this paper build urban competitiveness index system, using the analytic hierarchy process analysis and evaluation of Poyang Lake Ecological Economic Zone in the city's comprehensive competitiveness, propose the development of urban comprehensive competitiveness strategy measures.
\end{abstract}

\section{Introduction}

In the context of economic regional integration and rapid urbanization, how to avoid weaknesses, play to the advantages of the city, eliminate the negative impact of the inferior elements of urban development, one must think deeply and it has to be solved .In 2009,Jiangxi Province Poyang Lake Ecological Economic Zone in the proposed idea of this article during the major urban competitiveness on the basis of the analysis, based on the advantages and disadvantages of urban competitiveness of region and their respective characteristics, development countermeasures for Ecological Economic Zone in a new a region provided in the form of a certain research basis.

\section{The idea of the construction of Poyang Lake Ecological Economic Zone in Jiangxi Province}

Economics ecology and economics combine to form a new interdisciplinary, among the more authoritative definition is the famous ecological economist CostanzaR given: Ecological Economics from the widest range elaborated on the significance of the relationship between ecosystems and economic systems, these relationships we face many of the most pressing issues, including sustainable development, acid rain, global warming, species extinction, the distribution of wealth [1]. Ecological and economic area is to achieve ecological environment and socio-economic coordinated development of various fields of contemporary goal of sustainable development requirements of the region. Its main signs are: a good ecological environment and continually trend higher levels of balance, protection of natural resources reasonably and use; featuring ecological or green economy highly developed economy, reasonable structure, the overall competitive; mod-

ern ecological and cultural formation and development, democracy and the rule of law and integrity of a high degree of social civilization; beautiful environment of urban and rural people's living standard comprehensive into the rich stage, the fundamental control and basic elimination of environmental pollution [2].

Poyang Lake concentrated around the central city of Nanchang, Jiujiang, Yingtan, Jingdezhen, Xinyu, the best industrial base, scientific and cultural level of the highest level of urbanization in the best economy most closely connected region, just become Poyang Lake Economic Area development of the carrier, may provide for the realization of the green development of Jiangxi Poyang Lake Ecological Economic Zone, including some or all of the counties and cities as the core to the Poyang Lake in Nanchang, Jiujiang, Jingdezhen, Yingtan, Xinyu, Fuzhou City, the object of study in Nanchang, Jiujiang, Jingdezhen, Yingtan, Xinyu, Fuzhou six prefecture-level cities. 


\section{Ecological Economic Zone Urban Competitiveness Evaluation}

Poyang Lake Ecological Economic Zone in the urban competitiveness comprehensive evaluation and analysis, on the one hand, the city's comprehensive competitiveness make a reasonable evaluation and comparison of Poyang Lake city ties and the division of labor, on the other hand, it has an important guiding significance. I build urban competitiveness index system based on the use of the Analytic Hierarchy Process to determine the competitive-ness of cities, urban competitiveness broken down into a number of levels and a number of factors ${ }^{[3,4]}$, between the various factors comparisons and calculations, draw the elements of the importance of the weight, combined with the city in Jiangxi Statistical Yearbook statistical indicators data, and ultimately competitive score obtained in various cities, city comprehensive evaluation of the competitiveness of the various elements of urban competitiveness in-depth analysis.

\subsection{Build urban competitiveness evaluation index system}

Urban competitiveness is not directly measurable characteristic variables: the Urban competitiveness system a complex, the number of elements and environmental systems exist in a different way, and impose different latitudes and at all levels, which together integration, constitute the city's comprehensive competitiveness, deci-ded the value of the city's income. Urban Competitiveness is a comprehensive assessment of it involves a lot of aspects, how scientific and rational combination of many factors is the key to the evaluation in accordance with the principle of systematic, rational, forward-looking, taking into account City Competitiveness Index data objectivity, representativeness and availability, on the basis of indicators of scientific and comprehensive reflect the connotation of urban competitiveness and strive to select the level of urban economic, the city financial strength, urban infrastructure, urban education and culture, urban The ecological environment 5 level indicators and 21 secondary indicators to build urban competitiveness evaluation index system (Table. 1).

TABLE I

POYANG LAKE ECOLOGICAL ECONOMIC ZONE URBAN COMPETITIVENESS EVALUATION INDEX SYSTEM

\begin{tabular}{|c|c|}
\hline Level Indications & Secondary Indication \\
\hline $\begin{array}{l}\text { The Level of } \\
\text { urban economic }\end{array}$ & $\begin{array}{l}\text { Per capita gross domestic product (GDP), the secondary industry accounted for the proportion of gross } \\
\text { domestic product (GDP), the total retail sales of social consumer goods, the average annual residents spending }\end{array}$ \\
\hline $\begin{array}{ll}\text { City } & \text { financial } \\
\text { strength }\end{array}$ & $\begin{array}{l}50 \text { million yuan in fixed assets investment, and local revenues, urban and rural residents at the end of deposits, } \\
\text { the actual use of foreign capital }\end{array}$ \\
\hline $\begin{array}{l}\text { Urban } \\
\text { infrastructure }\end{array}$ & $\begin{array}{l}\text { Per capita area of urban roads, social employment proportion of the total population, per million people the } \\
\text { number of public transport vehicles, the number of doctors per million }\end{array}$ \\
\hline $\begin{array}{l}\text { Urban education } \\
\text { and culture }\end{array}$ & $\begin{array}{l}\text { Total profit of the high-tech industry, government science and technology institutions and research } \\
\text { Expenditures per million vocational secondary schools the number of students in the school, every } 100 \text { has a } \\
\text { number of books in public libraries }\end{array}$ \\
\hline $\begin{array}{l}\text { Urban ecological } \\
\text { environme }\end{array}$ & $\begin{array}{l}\text { Output value of comprehensive utilization of industrial pollution control project investment, industrial } \\
\text { wastewater discharge compliance rate, per capita green area green coverage, "three wastes }\end{array}$ \\
\hline
\end{tabular}

\subsection{City's Comprehensive Competitiveness Analysis}

(1)Judgment matrix sentence

Off matrix the value of each element reflects the understanding of the relative importance of various factors, generally divided into 91 to 9 and their reciprocal scaling method (see Table. 2) construction of Poyang Lake Ecological Economic Zone Urban Competitiveness judgment matrix:

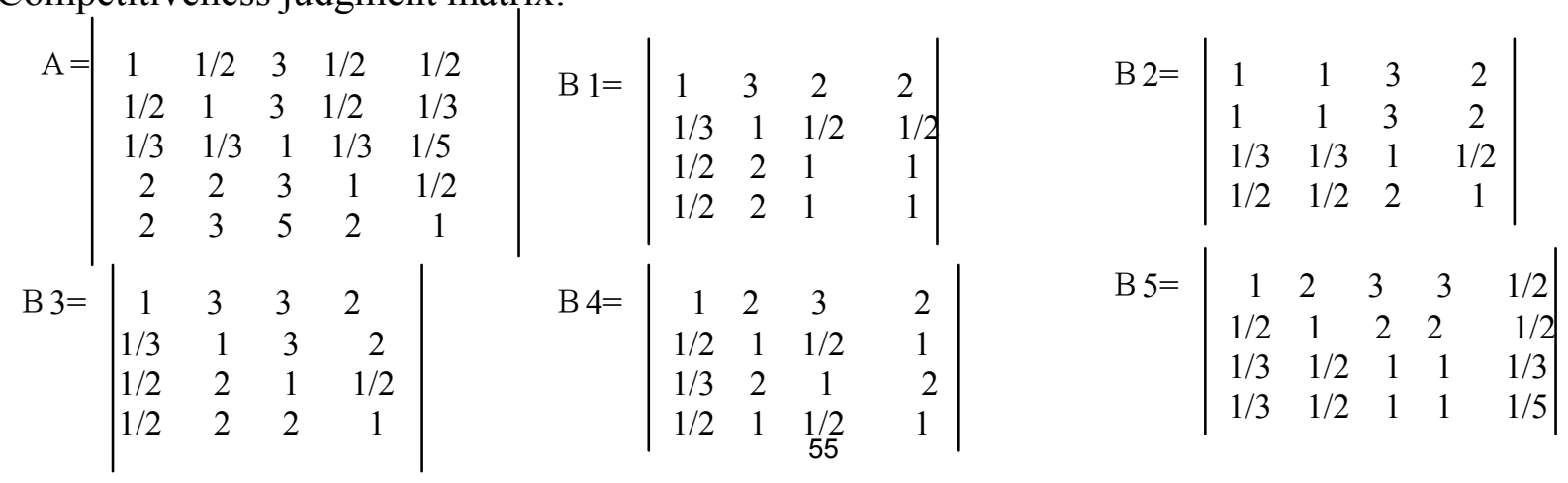


TABLE II

FACTOR COMPARISON BETWEEN TWO SCALE WEIGHT CONTROL

\begin{tabular}{cll}
\hline Degree & \multicolumn{2}{c}{ Defined } \\
\hline 1 & Equally important & Two-factor the same effect as \\
\hline 3 & Slightly stronger & A factor of slightly stronger than the other factors acting \\
5 & Strength & The role of a factor was stronger than another factor \\
7 & Strong & A strong factor in the magnitude of another factor \\
9 & Absolute intensity & A strong factor in the maximum possible on another factor \\
2468 & Above the middle of the scale value \\
Reciprovalue & $\begin{array}{l}\text { Compare values of } i \text { and } j \text {, given a scaling value for the scale values of } j \text { and } i \text { weights when comparing } \\
\text { countdown }\end{array}$
\end{tabular}

\section{(2) The Level of Single-sort Root}

According to the judgment matrix calculation is compared factor at the level of the relative weight of.

(1)Analyzing matrix: $\mathrm{A}=$ [aij] $\mathrm{N} \times \mathrm{n}, \mathrm{n}$ number of factors, aij, $\mathrm{i}$ indicators on the relative importance of the $\mathrm{j}$ index.

(2) The judgment matrix each column for the benefit of a technology: aij $=1 \mathrm{XKJ}=\mathrm{aij} \Sigma \mathrm{nk}, \mathrm{i}, \mathrm{j}=$ $1,2, \ldots, \mathrm{n}$.

(3) each column by normalization of judgment matrix is added to the line-by-line: $w i=\Sigma n j=1$, aij, $\mathrm{i}$ $=1,2, \mathrm{n}$.

(4) vector $\mathrm{W}=[\mathrm{w} 1, \mathrm{w} 2, \ldots, \mathrm{wn}] \mathrm{T}$ normalization: $\mathrm{wj}=\mathrm{wi} \Sigma \mathrm{nj}$ for $1 \mathrm{wj}, \mathrm{i}=1,2, \ldots, \mathrm{n}$.

(5)Finally, the obtained $\mathrm{w}=[\mathrm{w} 1, \mathrm{w} 2, \ldots, \mathrm{wn}] \mathrm{T}$ is the required eigenvectors, i.e. the relative weights of the hierarchy within the index weights.

TABLE III

POYANG LAKE ECOLOGICAL ECONOMIC ZONE IN THE CITY COMPETITIVENESS EVALUATION INDEX COMBIINATION OF WEIGHT

\begin{tabular}{|c|c|c|}
\hline Indicator & Index Item & Weights \\
\hline \multirow{4}{*}{$\begin{array}{l}\text { The urban economic level } \\
\text { (B 1) }\end{array}$} & GDP per capita ( C 1) & 0.067981 \\
\hline & Secondary industry accounted for the proportion of gross domestic product (GDP) (C 2) & 0.018893 \\
\hline & Retail sales (C 3) & 0.031713 \\
\hline & Residents of the average annual spending ( C 4) & 0.031713 \\
\hline & Local fiscal revenue ( C 5) & 0.063502 \\
\hline \multicolumn{2}{|c|}{ The city financial strength Local fiscal revenue ( C 6) } & 0.063502 \\
\hline \multirow[t]{3}{*}{ ( B 2) } & Urban and rural residents' deposits at the end ( $\mathrm{C} 7$ ) & 0.019660 \\
\hline & Amount of foreign capital actually utilized ( C 8) & 0.047843 \\
\hline & Per capita area of urban roads ( C 9) & 0.029807 \\
\hline \multirow{3}{*}{ Urban infrastructure (B 3) } & he social employment to the proportion of the total population ( $\mathrm{C} 10$ ) & 0.008284 \\
\hline & Per million people the number of public transport vehicles ( C 11) & 0.013905 \\
\hline & The number of doctors per million people( $\mathrm{C} 12)$ & 0.013905 \\
\hline \multirow{4}{*}{$\begin{array}{l}\text { City science, education } \\
\text { and culture (B 4) }\end{array}$} & High-tech industry total profit ( $\mathrm{C} 13$ ) & 0.089666 \\
\hline & Government research funding of science and technology institutions expenditure ( C 14) & 0.034245 \\
\hline & People vocational secondary school students ( C 15) & 0.049623 \\
\hline & Every hundred books in public libraries ( C 16) & 0.034245 \\
\hline \multirow{4}{*}{$\begin{array}{l}\text { Urban ecological } \\
\text { environment ( B 5) }\end{array}$} & Industrial pollution control project investment ( C 17) & 0.103950 \\
\hline & Industrial wastewater discharge compliance rate ( $\mathrm{C} 18$ ) & 0.066161 \\
\hline & Green space per capita ( C 19) & 0.037473 \\
\hline & Green coverag ( $\mathrm{C} 20)$ & 0.033358 \\
\hline
\end{tabular}

\section{(3) Consistency Test}

Calculating the consistency ratio CR (consistencCIRI where in CI = (lambda max $-n) /(n-1)$. Analyzing the consistency of the matrix is acceptable; Classifying matrix needs to be done with appropriate modifications when $\mathrm{CR} \geq 0.1$. 
(4) The Results

According to the above three steps, calculate the various statistical indicators of the right weight, eventually get various statistical indicators of the right combination of weight (Table 3).

2010 "Jiangxi Statistical Yearbook" check was 21 indicators of the original data, the use of SPSS 13.0 statistical software to standardize the raw data, the dimensionless combined weight hierarchical model of urban competitiveness given the combination of statistical indicators, ultimately obtained individual scores and composite score of each city competitiveness, and press the consolidated City score sort (Table 4).

TABLE IV

POYANG LAKE ECOLOGICAL ECONOMIC ZONE URBAN COMPETITIVENESS (2009)

\begin{tabular}{|c|c|c|c|c|c|c|}
\hline City & Nanchang & JiuJiang & Jindezhen & Yin $\tan$ & Xin $y u$ & Fu zhou \\
\hline Economic level & 0.2161 & -0.0863 & -0.0423 & 0.0076 & 0.0465 & -0.1416 \\
\hline Financial strength & 0.3755 & 0.0313 & -0.1263 & -0.1353 & -0.0745 & -0.0441 \\
\hline Infrastructure & 0.0176 & 0.0204 & -0.0365 & -0.0158 & 0.0439 & -0.0283 \\
\hline Education and culture & 0.1518 & -0.0403 & -0.0593 & -0.1014 & 0.2251 & -0.1759 \\
\hline Ecologicalenvironment & -0.0236 & 0.0078 & -0.1427 & 0.4691 & -0.0932 & -0.2174 \\
\hline
\end{tabular}

3. The Results of Analysis

According to the results in Table 4, in accordance with the city's comprehensive competitiveness ranking Poyang Lake Ecological Economic Zone belongs to the prefecture-level city is divided into three levels:

Nanchang is a Level 1 (overall competitiveness score of0.7374); Yingtan, Xinyu, Jiujiang belonging to the second level (overall competitiveness score of -0.0671 to 0.2242 ); Jingdezhen, Fuzhou is a Level 3 (overall competitiveness score of -0.6073 to -0.4071). evaluation results on analytic hierarchy process is basically consistent with the actual situation Nanchang is important cities in King City, Jiangxi Province and Poyang Lake Ecological Economic Zone in the center of the city, compared with the other five cities have obvious advantages.

the most comprehensive competitiveness; Yingtan City, Xinyu City, Jiujiang City in recent years, the development of faster, better ecological environment, enh-anced overall strength; Jingdezhen, Fuzhou is located in the peripheral circle of the Poyang Lake Ecological Economic Zone, ecological and environmental protection, and control is relatively poor, the low sustainability of the city, the city's comprehensive competitiveness weaker .

\section{References}

[1] C OSTANZAR,KINGJ.TheFirstDecadeofEcoloyArticle)[J]. EcologicalEco nomics, 1999,28:1 9

[2] the Liu Rong Yun Liang, Tianshuang Quan. Ecological Economic Zone in connotation and its theoretical basis [J]. Rural economy, 2004 (6): 2830.

[3] GU Chao-lin, Yu Tao Fang Nanjing city's comprehensive competitiveness Comparative Study [J] Social Sciences, 2002 (Supplement): 2028.

[4] Liusu Xia Yang Jian Road, Xi Yongzhong Yangtze River Delta urban competitiveness evaluation index system construction [J] Jiangsu Commercial Forum 2007 (6): 145147. 